\title{
Políticas públicas: marco legal para as bibliotecas escolares
}

\author{
Márcio Barbosa de Assis \\ Mestre; Universidade Federal de Lavras, Lavras, MG, Brasil; \\ marcio.assis@ufla.br; ORCID: https://orcid.org/0000-0002-2644-4262 \\ Ilsa do Carmo Vieira Goulart \\ Doutora; Universidade Federal de Lavras, Lavras, MG, Brasil; \\ ilsa.goulart@ ufla.br; ORCID: http://orcid.org/0000-0002-9469-2962
}

\begin{abstract}
Resumo: Considerando a biblioteca escolar como um espaço de formação de leitores e recurso pedagógico, apresentamos uma revisão de literatura sobre a legislação em prol da biblioteca escolar, sua estrutura, equipamentos, acervos, sua utilização, da importância de se ter um profissional qualificado e a interrelação do bibliotecário com os professores, a fim de que o processo de ensino e aprendizagem dos alunos seja facilitado e potencializado. Com o intuito de contribuir e fomentar o acesso ao livro e a utilização dele, o Governo Federal dispõe de marcos regulatórios para a política de biblioteca, do livro e da leitura. Discutimos também a necessidade de uma formação efetiva e continuada dos bibliotecários, professores e agentes de leitura, a fim de fortalecer a biblioteca como ambiente democrático de acesso ao conhecimento, para ações de leitura, a partir dos objetivos, funções e missão da biblioteca escolar. A biblioteca é um instrumento de desenvolvimento da cultura e também do currículo escolar, pois nutre a leitura e, consequentemente, gera o aprendizado. Mas para que esse processo seja efetivado, além de uma íntima parceria com os professores, é necessário também que as políticas governamentais sejam efetivadas, prevendo e consolidando os investimentos necessários à biblioteca escolar.
\end{abstract}

Palavras-chave: Biblioteca educacional; Biblioteca - Legislação; Biblioteca Escolar; Letramento

\section{Introdução}

Ao considerar o espaço de leitura em instituições escolares, como ambiente educacional de promoção e de incentivo à leitura e à formação de leitores, este texto tem por finalidade apresentar uma revisão de literatura sobre as legislações em prol da biblioteca escolar, sua estrutura, equipamentos, acervos, sua utilização, da importância de se ter um profissional qualificado e a interrelação do bibliotecário com os professores, a fim de que o processo de ensino e aprendizagem dos alunos seja facilitado e potencializado. 
Algumas normatizações têm direcionado, de modo específico, orientações em relação à biblioteca escolar, como a lei no 12.244 , de 24 de maio de 2010, que trata da universalização das bibliotecas nas instituições de ensino no Brasil. Em seu artigo $2^{\circ}$, a legislação define biblioteca escolar como uma “[...] coleção de livros, materiais videográficos e documentos registrados em qualquer suporte destinado a consulta, pesquisa, estudo ou leitura." (BRASIL, 2010). Ampliando um pouco mais esse conceito, o manifesto da IFLA/UNESCO apresenta a biblioteca como uma "[...] porta de entrada para o conhecimento, fornece as condições básicas para o aprendizado permanente, autonomia das decisões e para o desenvolvimento cultural dos indivíduos e dos grupos sociais." (INTERNATIONAL FEDERATION OF LIBRARY ASSOCIATIONS AND INSTITUTIONS - IFLA, 1994).

O interesse e a preocupação com a biblioteca escolar como espaço e recurso indispensável às escolas no Brasil é relativamente recente, iniciando-se especificamente na década de 1930, por meio de um movimento de renovação da educação e do ensino no país, chamado "Escola Nova". Um dos líderes desse movimento, o Prof. Anísio Teixeira, sustentava que cada escola deveria ter um espaço adequado e exclusivo para a pesquisa e a leitura. $\mathrm{O}$ movimento requeria a existência de uma biblioteca em cada escola e também outros recursos didático-pedagógicos (ORIÁ, 2017).

Atualmente, o Ministério da Educação (MEC) reconhece a necessidade e a importância da biblioteca escolar na escola, estando explicitado no Censo Escolar da Educação Básica de 2013 que a biblioteca escolar “[...] disponível nas escolas tem importância fundamental no processo de aprendizagem." (INSTITUTO NACIONAL DE ESTUDOS E PESQUISAS EDUCACIONAIS ANÍSIO TEIXEIRA - INEP, 2014, p. 33).

O Governo Federal, por meio do Ministério da Educação (MEC), tem produzido esforços a partir de políticas públicas em relação ao livro, como o Programa Nacional do Livro e do Material Didático (PNLD) e o Programa Nacional Biblioteca da Escola (PNBE), com o propósito de prover as escolas de educação básica pública com obras didáticas, pedagógicas e literárias, bem como com outros materiais de apoio à prática educativa, de forma sistemática, 
regular e gratuita (BRASIL, 2020a, 2020b). Iniciado em 1997, o PNBE propõe a promoção da cultura, incentivando a leitura, tanto aos alunos quanto aos professores, por meio da distribuição de obras literárias e de pesquisa para constituição de acervo nas bibliotecas escolares de todo o país. As bibliotecas escolares teriam o papel de ser o espaço de gerenciamento das obras e de favorecimento de acesso à leitura, contribuindo assim para a formação de leitores.

O PNBE tem como objetivo "[...] fornecer aos estudantes e seus professores material de leitura variado para promover tanto a leitura literária, como fonte de fruição e reelaboração da realidade, quanto a leitura como instrumento de ampliação de conhecimentos [...]", destacando também, como essencial, o "[...] aprimoramento das práticas educativas entre os professores." (BRASIL, 2020a).

Recentemente, o Governo Federal editou o Decreto n ${ }^{\circ}$ 9.099, de 18 de julho de 2017, em que faz modificações consistentes no Programa Nacional do Livro e do Material Didático (PNLD), ampliando seu alcance para as escolas comunitárias, confessionais ou filantrópicas sem fins lucrativos e que estejam conveniadas com o Poder Público. O art. $1^{\circ}$ desse decreto expõe sobre a disponibilização de:

[...] obras didáticas e literárias, de uso individual e coletivo, acervos para bibliotecas, obras pedagógicas, softwares e jogos educacionais [...], materiais de formação e materiais destinados à gestão escolar, entre outros materiais de apoio à prática educativa [...] (BRASIL, 2017).

Para Oriá (2017), embora haja uma ampliação do escopo do programa, entre os educadores e especialistas há um receio do esvaziamento do PNBE, tendo em vista que o novo PNLD já prevê a remessa de obras literárias para as escolas.

Alcântara (2013) destaca que a biblioteca escolar tem a função primordial de formar leitores e pesquisadores, além de conservação de seu acervo, o que fez da biblioteca uma guardiã de documentos (livros, revistas, jornais, materiais audiovisuais, sonoros, entre tantos outros tipos de suportes em que a informação pode ser armazenada). Originalmente, a palavra biblioteca é 


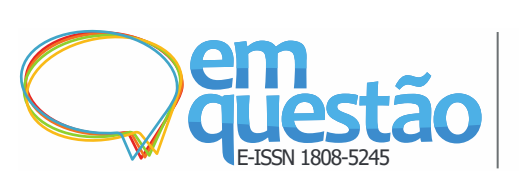

Políticas públicas: marco legal para as bibliotecas

escolares

Márcio Barbosa de Assis, Ilsa do Carmo Vieira Goulart

oriunda do grego bibliothéke, que significa “[...] lugar onde se guardam os livros [...]" (PIMENTEL; BERNARDES; SANTANA, 2007, p. 22). Contudo, convém que a biblioteca funcione como uma oficina de leitores, e não somente como um espaço onde os livros são armazenados e preservados (ALCÂNTARA, 2013; MENDES, 2012; MOURA, 2006). Milanesi (2002) apresenta a mudança que houve no início do século XX quanto à percepção da função da biblioteca, predominantemente de organização e armazenamento dos documentos para uma sistematização do acesso a essas informações.

Alcântara (2013) enfatiza a necessidade de estimular a utilização da biblioteca e de esta desenvolver habilidades para sua adequada utilização, pois a biblioteca escolar é um instrumento essencial para a aprendizagem, no que tange ao uso das diferentes fontes de informação e dos recursos tecnológicos, com o intuito de construir e adquirir o conhecimento, como destacam os Parâmetros Curriculares Nacionais (PCN) do Ensino Fundamental de Língua Portuguesa (BRASIL, 1997, 1998b), reconhecendo a biblioteca escolar como um espaço privilegiado para a aprendizagem, a ser explorado por professores e alunos. Os PCNs destacam que a biblioteca escolar é um excelente recurso para favorecer o processo de ensino e aprendizagem.

Contudo, é fundamental que o espaço da biblioteca conte com uma infraestrutura adequada de informação, composta por um acervo atualizado, preferencialmente informatizado, com acesso à internet e a bancos de dados, além de políticas de uso dos espaços e dos recursos e layout que propicie a aprendizagem (GASQUE, 2012). Os estudos de Oriá (2017) e Perrotti (1990) apontam que as bibliotecas públicas, comunitárias e escolares precisam estar fortalecidas e modernizadas, com o intuito de expandir e democratizar o uso do livro à população do país, de forma a desenvolver a leitura entre a população.

Nesta vertente argumentativa, questiona-se: o que as legislações trazem como orientações sobre a biblioteca escolar? De que forma a biblioteca escolar em sua estrutura, equipamentos, acervos, sua utilização e em relação ao profissional pode contribuir como espaço educativo e de promoção da leitura?

Em busca de respostas, assume-se uma pesquisa qualitativa de caráter bibliográfico, a partir da revisão de literatura dos documentos oficiais que tratam 
de modo específico da biblioteca escolar, a partir de uma análise reflexiva das políticas públicas, como Política Nacional do Livro (BRASIL, 2003) e a Lei das Bibliotecas Escolares (BRASIL, 2010), Política Nacional do Livro (BRASIL, 2011) e da Política Nacional de Leitura e Escrita (BRASIL, 2018), como também do Programa Nacional do Livro e do Material Didático (PNLD) e do Programa Nacional Biblioteca da Escola (PNBE), em interlocução com diferentes autores que discutem o assunto.

Deste modo, ao abordar as legislações em vigência, a respeito do livro e da biblioteca escolar, organiza-se a reflexão em três seções: na primeira direciona-se à missão e aos objetivos da biblioteca escolar; em seguida, abordase o uso da biblioteca escolar como recurso educacional e, por fim, discute-se a respeito da escola e do bibliotecário ou professor responsável pela biblioteca escolar.

\section{Legislação vigente sobre o livro e a biblioteca escolar}

Para contribuir e fomentar o acesso ao livro e a utilização dele, o Governo Federal dispõe de marcos regulatórios e legislativos para a política de biblioteca, do livro e da leitura, instituindo a Política Nacional do Livro e a Lei das Bibliotecas Escolares, por meio das Leis 10.753/2003 e 12.244/2010, respectivamente (BRASIL, 2003, 2010).

A Lei $n^{\circ} 10.753$, de 30 de outubro de 2003, em seu art. $1^{\circ}$ apresenta o direito de acesso e uso do livro como meio fundamental e insubstituível da difusão da cultura e transmissão do conhecimento, “[...] do fomento à pesquisa social e científica, da conservação do patrimônio nacional, da transformação e aperfeiçoamento social e da melhoria da qualidade de vida." (BRASIL, 2003) a todo cidadão brasileiro e reconhece a necessidade e urgência de preparar a população com o uso do livro, para o progresso econômico, político e social desta, sendo o livro, portanto, fator essencial para a promoção da democratização do conhecimento.

O parágrafo único do art. $7^{\circ}$ da Lei $n^{\circ} 10.753 / 2003$ relaciona e atribui ao Poder Executivo a obrigatoriedade da implementação de "[...] programas anuais 
para manutenção e atualização do acervo de bibliotecas públicas, universitárias e escolares [...]" (BRASIL, 2003). Considerando essa exigência, o governo sanciona a Lei 12.244, de 24 de maio de 2010, que trata da universalização das bibliotecas nas instituições de ensino no país, garantindo que cada escola tenha uma biblioteca que possa atuar como importante aliado na aprendizagem das crianças e jovens, funcionando como um privilegiado equipamento cultural nas escolas.

Segundo Oriá (2017), a Lei 12.244/2010 representa um grande avanço quanto à infraestrutura das escolas. Contudo, essa realidade é quase uma utopia, por considerar que as políticas públicas não preveem condições reais para se efetivar a mencionada lei. $\mathrm{O}$ autor relaciona diversas lacunas quanto à operacionalização desta lei, como a ausência de dispositivos que produzam ou garantam seu cumprimento. Não constam na lei os responsáveis pela implantação das bibliotecas nas escolas, a designação dos recursos orçamentários, como serão criadas e outras instruções que são fundamentais para a efetivação da universalização das bibliotecas nas instituições de ensino.

Em $1^{\circ}$ de setembro de 2011, o Governo Federal sancionou o Decreto ${ }^{\circ}$ 7.559, que apresenta o Plano Nacional do Livro e da Leitura (PNLL), no qual aponta dispositivos referentes à importância da biblioteca para a promoção de uma sociedade mais democrática, pois considera o acesso ao livro e à informação mecanismos fundamentais para a formação da cidadania das pessoas. O PNLL “[...] consiste em estratégia permanente de planejamento, apoio, articulação e referência para a execução de ações voltadas para o fomento da leitura no País." (BRASIL, 2011).

Em 12 de julho de 2018, foi instituída a Política Nacional de Leitura e Escrita, através da Lei $n^{\circ}$ 13.696. No art. $1^{\circ}$ a lei define "[...] a Política Nacional de Leitura e Escrita como estratégia permanente para promover o livro, a leitura, a escrita, a literatura e as bibliotecas de acesso público no Brasil." (BRASIL, 2018).

Com a promulgação da Lei $n^{\circ} 13.696 / 2018$, é notória a importância das bibliotecas como forma de acesso aos livros e outros suportes que promovam a 
leitura, bem como a necessidade de uma formação efetiva e continuada dos professores, bibliotecários e agentes de leitura, a fim de fortalecer a biblioteca como ambiente democrático de acesso ao conhecimento, para ações de leitura.

A Lei $\mathrm{n}^{\circ}$ 13.005, de 25 de junho de 2014, institui o Plano Nacional de Educação (PNE), que prevê estratégias para a implantação de bibliotecas escolares. Embora não apresente claramente alguma meta, o item 7.33 determina que o PNE deve:

[...] promover, com especial ênfase, em consonância com as diretrizes do Plano Nacional do Livro e da Leitura, a formação de leitores e a capacitação de professores, bibliotecários e agentes da comunidade para atuar como mediadores da leitura, de acordo com a especificidade das diferentes etapas do desenvolvimento e da aprendizagem. (BRASIL, 2014).

Embora, com toda gama de decretos e leis que subsidiam as estratégias de políticas públicas relacionadas ao livro, à leitura e à biblioteca, na análise de Oriá (2017), há necessidade de maior articulação entre essas políticas, do livro e da leitura, com as políticas educacionais. Segundo ele, os legisladores poderiam ter estabelecido metas específicas no atual PNE, com o intuito de garantir a efetiva universalização das bibliotecas escolares no país.

\subsection{Missão e objetivos da biblioteca escolar}

De acordo com a IFLA (2000, p. 1), a biblioteca escolar tem a missão de promover "[...] serviços de apoio à aprendizagem e livros aos membros da comunidade escolar, oferecendo-lhes a possibilidade de se tornarem pensadores críticos e efetivos usuários da informação, em todos os formatos e meios." Estes precisam ser oferecidos, sempre, em parceria com os professores, uma vez que, ao trabalharem em conjunto, as ações podem influenciar " [...] o desempenho dos estudantes para o alcance de maior nível de literacia na leitura e escrita, aprendizagem, resolução de problemas, uso da informação e das tecnologias de comunicação e informação.” (IFLA, 2000, p. 2).

Portanto, a biblioteca escolar tem o potencial de integrar todo o processo educativo das escolas, mas não como uma estrutura independente, a qual cria e executa projetos e tarefas desassociadas dos programas propostos nos currículos 
e na prática docente. A IFLA (2000) apresenta os objetivos da biblioteca escolar como sendo essenciais para a aplicação dos serviços básicos da biblioteca na escola, de forma a cumprir seu papel de apoio no processo de ensino e aprendizagem, na cultura, no uso da informação e no desenvolvimento da competência da leitura e escrita. Seguem alguns objetivos da biblioteca escolar elencados pela IFLA (2000, p. 2-3):

[...] desenvolver e manter nas crianças o hábito e o prazer da leitura e da aprendizagem, bem como o uso dos recursos da biblioteca ao longo da vida;

oferecer oportunidades de vivências destinadas à produção e uso da informação voltada ao conhecimento, à compreensão, imaginação e ao entretenimento;

apoiar todos os estudantes na aprendizagem e prática de habilidades para avaliar e usar a informação, em suas variadas formas, suportes ou meios [...];

organizar atividades que incentivem a tomada de consciência cultural e social, bem como de sensibilidade;

trabalhar em conjunto com estudantes, professores, administradores e pais, para o alcance final da missão e objetivos da escola;

$[\ldots]$

promover leitura, recursos e serviços da biblioteca escolar junto à comunidade escolar e ao seu derredor.

É importante que essas funções apresentadas sejam exercidas nas bibliotecas, através do desenvolvimento de suas políticas e dos serviços disponibilizados pelos profissionais que atuam nesses espaços, sempre em consonância com o currículo escolar e o corpo docente. É fundamental que o currículo escolar, os professores e a biblioteca estejam ordenados para o desenvolvimento e a produção da leitura dos alunos, realizando atividades que provoquem o gosto pela leitura, que apoiem a aprendizagem das crianças, estimulando a conscientização cultural e social, que são essenciais para a formação da cidadania dos estudantes, com compreensão e sensibilidade.

De acordo com Moura (2006) e Vieira (2013), a biblioteca escolar tem como objetivo tornar-se o centro cultural e de leitura nas escolas, trabalhando concomitantemente com os alunos e professores de forma continuada, pois é um lugar privilegiado para se estimular o aprendizado e o gosto pela leitura, sempre procurando fomentar o interesse pelos livros e pela leitura. Hillesheim e Fachin (2004) veem a biblioteca como um elo entre professor e aluno, na promoção da 
pesquisa e da leitura, sendo um importante instrumento na formação educacional e cultural dos discentes.

Para Fragoso (2002) e Vieira (2013), a principal função da biblioteca escolar é dar apoio ao sistema educacional, contribuindo para o desenvolvimento do ensino. Para tanto, como compromisso assumido, deve-se disponibilizar material bibliográfico adequado, de forma organizada e acessível aos alunos e professores. Fragoso (2002), Neves e Ramos (2010) e Perrotti (1990) destacam a biblioteca como um centro ativo de aprendizagem, com foco no processo pedagógico proposto pela escola, sempre integrado à comunidade escolar, e não um espaço isolado, como se fosse apenas um depósito de livros.

Campello (2012, p. 7) enfatiza que a biblioteca escolar é “[...] mais do que estoque de conhecimentos [...]", podendo "[...] constituir-se em um espaço adequado para desenvolver nos alunos o melhor entendimento do complexo ambiente informacional da sociedade contemporânea.".

Na mesma direção, Durban Roca (2012, p. 24) justifica que a existência da biblioteca escolar não se refere à estrutura organizacional, de serviços bibliotecários, mas da finalidade "[...] como recurso educacional facilitador do desenvolvimento de processos de ensino-aprendizagem e de práticas de leitura, e, consequentemente, sua conceituação como agente pedagógico [...]”, de modo a contribuir com o desenvolvimento do projeto curricular da instituição.

Ratificando o exposto, Fragoso (2005) identifica a biblioteca como um centro de aprendizagem, sempre integrada ao processo pedagógico da escola, pois ela tem o compromisso de subsidiar a comunidade escolar com informação e leitura de qualidade, sempre de acordo com o contexto dos alunos. Segundo a autora, convém que a biblioteca priorize projetos de leitura, a partir de ações que produzam o interesse por sua utilização, sempre em consonância ao currículo escolar e à prática pedagógica dos docentes.

Por sua vez, Fragoso (2002) relaciona alguns objetivos da biblioteca, os quais entende como fundamentais. Ela cita a importância de cooperação com o currículo escolar, a partir das necessidades dos alunos e professores; o auxílio e a orientação nas pesquisas, de forma a tornar o usuário mais autônomo em suas 
consultas, além de proporcionar, tanto materiais quanto serviços bibliotecários aos seus leitores.

Entre os objetivos essenciais da biblioteca escolar destaca-se a interação do bibliotecário com o professor e o aluno, sendo a biblioteca subsidiária de todo o processo de ensino e de aprendizagem, facilitando o acesso ao ambiente da biblioteca e, sobretudo, o acesso aos acervos existentes, de forma que o aluno possa desenvolver a habilidade de encontrar, selecionar e avaliar os materiais de leitura a serem utilizados.

Fragoso (2002) relaciona em duas categorias as funções as quais considera como fundamentais para um bom desempenho da biblioteca escolar, identificadas como função educativa e função cultural. Em sua função educativa, a biblioteca deve promover a autonomia dos seus usuários, para a pesquisa e para a utilização do acervo, também na formação de bons hábitos com os materiais bibliográficos e equipamentos. E, ainda, disponibilizar bibliografias adequadas para o currículo escolar. Já na função cultural, a biblioteca pode favorecer a leitura, contribuindo além do currículo escolar, oferecendo diversidade de materiais e conteúdos para a leitura.

Caldin e Fleck (2004) concordam sobre a missão da biblioteca escolar de desempenhar funções educativas, culturais e técnicas, com o intuito de esse espaço se tornar um centro de informação, subsidiando as atividades curriculares da escola, sempre integrada à prática docente. As autoras discriminam essas funções como apresentadas na sequência.

[...] funções educativas: o fomento da leitura; o fomento da pesquisa; o desenvolvimento da criatividade; a educação para o lazer; a informação e orientação para a vida. [...] funções culturais: promover, de forma interdisciplinar, diversas atividades culturais no espaço da biblioteca como exposições, concursos literários, saraus literários, feiras de ciências, entre outras; [...] funções técnicas: gerenciar e organizar os recursos informacionais; explorar esses recursos e difundi-los à comunidade escolar; facilitar o acesso a esses recursos. (CALDIN; FLECK, 2004, p. 156).

Contudo, para que se alcance estes objetivos, entre outros quesitos é fundamental que a biblioteca tenha em seu comando um profissional habilitado para essas tarefas, que seja consciente e sensível às demandas dos docentes e 
discentes, mantendo a biblioteca atraente, utilizando as técnicas biblioteconômicas e pedagógicas para promover a construção do conhecimento, pois de nada serve uma bela biblioteca, com acervo adequado, espaço amplo e bonito, se não trabalhar concomitantemente com o corpo docente da escola, na busca contínua dos objetivos aqui expostos, ou seja, na produção da aprendizagem (FRAGOSO, 2002; PERROTTI, 1990).

É relevante ressaltar que o profissional habilitado, com competência técnica para a gestão da biblioteca escolar, como definido pela lei $\mathrm{n}^{\circ} 4.084$, de 30 de junho de 1962 e pela lei no 9.674, de 25 de junho de 1998 (BRASIL, 1962, 1998a), é o bacharel em Biblioteconomia. Contudo, como é apresentado por Fragoso (2002), a maior parte das bibliotecas escolares no Brasil não conta com o profissional bibliotecário para administrar e desenvolver os trabalhos biblioteconômicos nesse espaço. Na seção seguinte serão discutidas as ações específicas da biblioteca escolar.

\subsection{O uso da biblioteca escolar como recurso educacional}

As bibliotecas escolares podem ser pensadas como ambientes estimuladores do aprendizado, contribuindo para a formação e construção do conhecimento dos alunos, proporcionando momentos de leitura, seja esta feita pelo aluno ou pelo professor. São momentos como estes que ajudam os discentes a desenvolverem suas aptidões, capacidades e habilidades e a se identificarem na sociedade como seres autônomos, criativos, capazes de contribuir com o meio em que vivem.

A biblioteca escolar ainda se mostra marcada por visões distorcidas de sua finalidade primordial, muitas vezes sendo vista como um lugar estático. Por isso, deixa de ser reconhecida como um ambiente dinâmico e interativo, com grande potencial de motivação à aprendizagem, capaz de promover a interação entre os envolvidos na instituição escolar - como os docentes, os discentes, os funcionários -, estendendo uma interação, possivelmente, com a comunidade, constituindo um espaço acolhedor, agradável e prazeroso (GASQUE, 2012).

Na mesma vertente, tem-se a visão de que o cerne da biblioteca escolar está em subsidiar os professores e alunos com informação adequada e suficiente 
para fomentar a aprendizagem, estimulando e facilitando o acesso ao conhecimento construído nas salas de aula e na própria biblioteca (FRAGOSO, 2005).

Gasque (2012) enfatiza que a biblioteca escolar compõe o processo educacional, tendo um papel dinâmico e efetivamente participativo na escola, democratizando o acesso e o uso da informação. A autora destaca uma concepção e visão mais amplas de biblioteca como espaço integrado à escola, atuando ativamente e subsidiando toda estrutura de ensino e aprendizagem, em contraposição a outra visão distorcida, que é a de biblioteca como espaço isolado. Bezerra (2008) também compartilha de tal concepção, ao dizer que a biblioteca tem a função de fornecer informações aos docentes e discentes, pois compreende que a biblioteca é um excelente recurso para subsidiar o conteúdo a ser desenvolvido nas salas de aula e no próprio espaço da biblioteca.

Britto (2016) compreende a biblioteca como espaço de encontros, de relações do ser humano com a arte, com a ciência, com a filosofia, a história, um ambiente efetivamente social e político, dinâmico, pois incita o pensar, a imaginação, a construção do conhecimento a partir da leitura e da reflexão. Para Britto (2016), Moura (2006) e Perrotti (1990), a biblioteca tem como princípio a formação do leitor e deve sempre contribuir para a construção do ensino e da aprendizagem, em plena parceria com os professores, de forma a levar os discentes a superarem seus limites, conscientizando-os de seu papel individual e coletivo dentro da sociedade em que está inserido.

Durban Roca (2012) levanta questões sobre a utilização da biblioteca escolar, constituída como recurso educacional, e as ações que podem ser feitas para viabilizar sua organização e promover o funcionamento, a partir do pressuposto de que a biblioteca favoreça o progresso de habilidades intelectuais e de práticas leitoras dos discentes. Considera, ainda, que a biblioteca na escola tem como fundamento o apoio ao desenvolvimento do projeto curricular, sendo esse aspecto primordial para justificar a existência da biblioteca.

A partir dos critérios do Manifesto da Unesco sobre biblioteca escolar (IFLA, 1994), Pimentel, Bernardes e Santana (2007) destacam que a biblioteca 
tem um papel preponderante no processo educacional, pois favorece o conhecimento mútuo, compartilhado, tendo em vista que a educação e a aprendizagem não ocorrem unilateralmente, com o foco apenas no aluno, mas sim de maneira participativa, entre o professor, os alunos e os instrumentos que a escola proporciona, como a biblioteca.

Bezerra (2008), Campello (2010) e Durban Roca (2012) apresentam uma concepção de biblioteca democratizada, estando disponível aos estudantes não somente no horário escolar, facilitando seu acesso, procurando dar autonomia aos alunos para utilização desse espaço com todos os seus recursos e materiais oferecidos. A biblioteca pode incentivar a leitura, em seu próprio ambiente e nos lares dos usuários. Outro projeto a ser desenvolvido, segundo Durban Roca (2012), é em relação às necessidades especiais de seus usuários como, por exemplo, a compensação de desigualdades educacionais, sendo este um trabalho de grande impacto social. O que dá sentido à existência da biblioteca é sua utilização, tanto pelos alunos quanto pelos professores, aliás, pelos alunos com seus professores, assim ela exerce sua função de apoio aos processos de ensino e de aprendizagem. Os professores podem utilizar a biblioteca como uma estratégia didática, aplicada em situações específicas de sua prática.

Um acervo de livros por si só não se constitui em biblioteca escolar, pode-se configurar em apenas um amontoado de papéis. As bibliotecas trazem em seu bojo a ideia de espaço dinâmico e interativo, com a produção intelectual humana que visa a criação de conhecimento e a inovação em benefício da humanidade. Constituindo-se como um lugar de aprendizagem, as bibliotecas promovem a leitura, que, por sua vez, permite o diálogo com outras formas de pensamento, superando os limites de cada leitor e ampliando a visão de mundo (GASQUE, 2012).

Na mesma vertente, segundo Durban Roca (2012), Oriá (2017) e Perrotti (1990), a biblioteca escolar é vista como um recurso facilitador de processos de ensino e de aprendizagem. Tal perspectiva atribui à biblioteca escolar grande potencial para ser uma aliada no processo de ensino e de aprendizagem na escola, um espaço adequado para que seja desenvolvida a fruição da prática da pesquisa e, sobretudo, da leitura. 
Nessa direção, Gasque (2012) considera a biblioteca de forma integrada à escola, ao seu currículo, compondo todo o processo educacional. A autora não compreende a biblioteca apenas como um espaço estático, onde os livros são guardados, mas de maneira dinâmica, atuante e efetiva, como parceira dos docentes, envolvendo-se no aprendizado dos alunos. Contudo, a autora apresenta alguns elementos que considera fundamentais para que a biblioteca escolar seja altamente participativa no processo de ensino e aprendizagem, como segue:

- Multiusabilidade: os espaços são usados como salas ambientes, com layout apropriado, em que os vários recursos são disponibilizados simultaneamente, propiciando acesso a diferentes pontos de vista.

- Favorecimento da socialização: os aprendizes aprendem a conviver e a respeitar os outros de várias faixas etárias e características diferenciadas. Os espaços são diferenciados pela função, por exemplo, centro cultural, leitura, pesquisa.

- Integração do planejamento com a coordenação/assessoria pedagógica e professores: possibilita sistematicamente atividades de resolução de problemas, de fomento à leitura e programas culturais.

- Formação contínua: propicia aos profissionais da educação, bibliotecários, assistentes, estagiários e professores, fundamentação básica na área da educação e de biblioteconomia, a fim de concretizar uma proposta pedagógica voltada para a investigação e, em consequência, para a aprendizagem da busca e do uso da informação.

- Caráter pedagógico/cultural: entende os serviços técnicos da biblioteca somente como uma faceta que propicia a aprendizagem, não devendo ser a ação nuclear.

- Ações voltadas para o letramento informacional: como ação nuclear permeia os processos de ensino-aprendizagem. A orientação aos usuários e os programas de formação, por exemplo, devem ser estendidos aos professores e ter a cooperação deles.

- Prontidão no uso das novas tecnologias: como resultado do uso adequado e sistematizado dessas ferramentas. (GASQUE, 2012, p. 156-157).

A ação nuclear da biblioteca, segundo Gasque (2012), é facilitar o acesso aos seus materiais e subsidiar os alunos nos processos de ensino e aprendizagem, oferecendo um ambiente adequado e agradável, propício para que haja a socialização entre os alunos e professores, sempre com um caráter educacional e cultural.

A partir dos critérios apresentados por Gasque (2012), podemos pensar em uma biblioteca a ser estruturada com layout e com recursos que favoreçam a convivência e o relacionamento dos alunos, que promovam um ambiente 
agradável para permanência deles, adequado à leitura, ao lazer, ao descanso, e, portanto, à socialização. Quando pensamos a leitura literária, é importante que esses princípios destacados sejam adequados, pois a leitura é uma atividade imbuída de afetividade.

À biblioteca cabe favorecer o acesso à informação, sendo mediadora nos processos de aprendizagem dos alunos, isto é, mais do que organizar a informação, a preocupação dos bibliotecários está em auxiliar os usuários a encontrá-la e usá-la. Assim, a biblioteca se torna um espaço ativo de aprendizagem, um ambiente em que as atividades promovidas se constituem em elementos atrativos para os usuários (CAMPELLO, 2010; GASQUE, 2012; PERROTTI, 1990).

Segundo Durban Roca (2012) e Perrotti (1990), a biblioteca escolar é de grande utilidade na construção do ensino e da aprendizagem, porque tem o potencial de facilitar o desenvolvimento de atividades pelas quais as crianças e os jovens podem aprender em situações de interação comunicativa. De acordo com Durban Roca (2012), essas situações podem ser de dois tipos: os trabalhos de pesquisa e as atividades de leitura. Essas duas situações possibilitam a interação com a leitura, com conteúdo de materiais diversos, impressos ou digitais, e, ao mesmo tempo, permite a interação e o diálogo entre o aluno e o professor, o que pode ocorrer individual ou coletivamente, e entre os colegas de aula, na elaboração de trabalhos em grupo ou nas apresentações daquilo que foi elaborado.

Durban Roca (2012, p. 33) relaciona algumas indicações para a implementação prática do uso pedagógico da biblioteca na escola:

A escola deve dispor de uma proposta estruturada de possibilidades de uso efetivo da biblioteca como recurso facilitador de aprendizagem e de práticas de leitura;

As atividades realizadas deverão se relacionar a atividades didáticas localizadas dentro do desenvolvimento curricular da escola e do cotidiano de sala de aula;

A proposta de utilização pode vir a partir de uma matéria ou disciplina, de uma área curricular ou até mesmo de um projeto interdisciplinar;

A atividade pode ser encaixada no contexto de um nível educacional, um ciclo ou de um projeto mais geral da escola; 
É necessário estabelecer uma contínua interação entre sala de aula e biblioteca que remeta ao planejamento de atividades de acordo com o conteúdo dos projetos de trabalho.

Concebendo a biblioteca escolar como um elemento educacional e não, simplesmente, como um elemento físico, percebemos que este ambiente se constitui num instrumento com função de apoio pedagógico, de maneira interdisciplinar, pois tem como finalidade subsidiar o processo de ensino desenvolvido nas escolas, colaborando substancialmente para a qualidade do ensino. Por isso, a figura do bibliotecário ou do profissional responsável por atuar no espaço da biblioteca escolar é tema da seção seguinte.

\subsection{A escola e o bibliotecário/professor responsável pela biblioteca: uma importante parceria}

Ao apresentar a biblioteca escolar como um espaço privilegiado para a aprendizagem, Campello (2010) considera que o ideal seria a administração por um bibliotecário qualificado, com uma equipe adequada, treinada para fornecer serviços à comunidade escolar, constituindo-se em um espaço coletivo no qual sejam compartilhados recursos didáticos, em conformidade com as metodologias adotadas em cada escola (CAMPELLO, 2010; IFLA, 1994).

Embora seja uma regulamentação e uma proposição bastante discutida em diferentes ações das políticas públicas no Brasil, essa concepção não remete às condições reais de atuação dos profissionais nas escolas públicas. Bicheri e Almeida Júnior (2013) destacam que há grande incoerência entre a teoria (legislação) e a prática (realidade das bibliotecas), pois muitas bibliotecas escolares não contam com um profissional bibliotecário e, em muitos lugares, não são oferecidas estruturas para o desenvolvimento de atividades que possibilitem ou promovam uma atuação social conforme discutidos teoricamente e legalmente.

Atualmente, ocorre que nas bibliotecas das escolas públicas atuam professores ou funcionários administrativos, os quais procuram exercer o papel do bibliotecário, não tendo uma preparação ou algum tipo de treinamento para esta função (BICHERI; ALMEIDA JÚNIOR, 2013). 
Durban Roca (2012) enfatiza que a biblioteca, ao ser implementada na escola, constitui um suporte à prática docente, com o objetivo de promover a concretização do currículo escolar, com um planejamento que ordene suas atividades utilizando esse espaço. Pode ser considerada um recurso educacional e estar integrada aos projetos educacionais e curriculares da escola, sendo assim um elemento de apoio aos docentes, de forma a agregar os processos de ensino e de aprendizagem. Diante disso, a biblioteca na escola constitui-se como um recurso mediador nesse processo, o que atribui aos profissionais responsáveis por ela a função de colaborar com os professores, apresentando-se como referenciais quanto às questões relacionadas à formação literária, conteúdos de leitura e, sobretudo, na competência informacional (DURBAN ROCA, 2012; MOURA, 2006; PERROTTI, 1990).

Nesta perspectiva, a biblioteca pode se envolver efetivamente e com dinamicidade em ações que estimulem a leitura, através dos recursos próprios da biblioteca, como livros e outros instrumentos de leitura, pois como argumenta Durban Roca (2012), essa é a principal função da biblioteca escolar. Assim, a biblioteca torna-se um grande recurso na mediação dos processos de ensinoaprendizagem, pois assegura ações de valor pedagógico dentro da escola, propiciando um ambiente de aprendizagem. Tais argumentos conferem ao profissional responsável pela biblioteca a função de mediador do processo de formação de leitores. A autora destaca alguns elementos técnicos que contribuem nesse processo, como “[...] instalações e equipamentos diferentes dos existentes em sala de aula, materiais de qualidade em variados suportes e pessoal de apoio que facilita os processos, dispensando materiais." (DURBAN ROCA, 2012, p. 26).

Durban Roca (2012) e Perrotti (1990) propõem que a biblioteca escolar conte com o apoio do professor, para que todas as estratégias promovidas pela biblioteca a fim de subsidiar o aprendizado dos alunos sejam feitas em íntima parceria com os professores. Afinal, são eles quem estimulam os alunos a utilizarem a biblioteca, promovendo significado aos estudantes. Uma das ações dinamizadas pelo profissional responsável da biblioteca pode ser o apoio ao 
trabalho dos docentes, funcionando como instrumento pedagógico, dentro de uma ação curricular, atendendo demandas da prática docente.

Neste sentido, Durban Roca (2012) e Perrotti (1990) veem a biblioteca escolar como um recurso, não somente como um serviço oferecido às escolas. Para que os membros da escola tenham essa percepção, é necessário que haja um trabalho da biblioteca em consonância, com o currículo, o docente e os alunos. Para Durban Roca (2012), o bibliotecário ou profissional responsável tem grande contribuição no processo educacional, na implementação de serviços que sejam alinhados aos programas de ensino desenvolvidos na escola.

Para Bicheri e Almeida Júnior (2013), Moura (2006) e Perrotti (1990), a biblioteca escolar é o espaço privilegiado para a formação de leitores, sobretudo se favorecido pela parceria entre o professor e o bibliotecário. Na mesma direção, para Campello (2010, p. 15),

Uma boa biblioteca possui coleção selecionada em função dos interesses da comunidade a que serve. Não é um amontoado de livros recebidos por doação ou enviados por órgãos governamentais que, embora com a melhor das intenções, não conhecem a fundo as necessidades da escola. Ela deve ser organizada de forma a permitir que o livro ou material certo seja encontrado com facilidade e rapidez.

Durban Roca (2012) e Neves e Ramos (2010) não compreendem a biblioteca somente como depósito de materiais, livros, ou até mesmo equipamentos, mas sim como um espaço de recursos, mesmo que a serviço da aprendizagem. Assim, o bibliotecário precisa considerar este espaço como uma ferramenta no contexto da aprendizagem, compreendendo que há interação dos seus recursos no processo de ensino e aprendizagem, como um instrumento aos docentes para o estímulo e aperfeiçoamento da prática da leitura, pois para Durban Roca (2012, p. 26), “[...] a tônica deve ser posta na utilização da biblioteca como meio de ensino e não como serviço bibliotecário gerado por um centro de recursos.".

Bicheri e Almeida Júnior (2013) e Perrotti (1990) enfatizam que a biblioteca é um instrumento de desenvolvimento da cultura e também do currículo escolar, pois fomenta a leitura e, consequentemente, o aprendizado, 
estimulando a criatividade e a comunicação, sem perder seu perfil recreativo devido à diversidade literária que contém seu acervo. Descrevem, ainda, a necessidade de uma atuação mais eficaz do bibliotecário ou do responsável pelas ações deste espaço. Para Bicheri e Almeida Júnior (2013), pouco adianta a escola manter em seu recinto uma biblioteca bem localizada, com decoração atraente, com mobiliário adequado e tecnologia, com acervo atualizado e diversificado para atender a comunidade escolar, se na biblioteca não houver um profissional que esteja atento aos currículos escolares e não mantenha contínua interação com os docentes para que os serviços ali oferecidos sejam convergentes com os conteúdos desenvolvidos pelos professores. Um profissional engajado na escola, que se interessa pela formação dos alunos, que é participativo, comunicativo e criativo, de forma a agregar outros conhecimentos ao processo de aprendizagem dos discentes, sempre em consonância às propostas de ensino da escola e dos professores.

Durban Roca (2012) propõe algumas tarefas e ações para o desenvolvimento da biblioteca escolar como recurso educacional e agente interdisciplinar para apoio pedagógico. Das tarefas e ações apresentadas pela autora, para que a biblioteca escolar se consolide como um efetivo recurso educacional, apoiando e subsidiando o processo pedagógico, destacamos a necessidade de a biblioteca realizar atividades culturais e também com o objetivo de promoção da leitura. Tais ações devem também envolver os familiares dos alunos, de forma que estes possam contribuir na formação e no desenvolvimento literário das crianças.

É importante que o bibliotecário escolar participe do projeto pedagógico da escola, que esteja envolvido com os professores, com os alunos e também com os funcionários e familiares, atuando de forma cooperativa e participativa em cada um desses grupos, procurando dinamizar o espaço da biblioteca para favorecer o processo de ensino e aprendizagem dos discentes. O bibliotecário tem a responsabilidade de mediar a relação entre a escola e a biblioteca, a produção do ensino que é realizada em sala de aula com o acesso à leitura, para que a aprendizagem seja potencializada. A parceria estabelecida pelo bibliotecário com os demais grupos envolvidos na escola pode proporcionar 
grandes benefícios, oriundos da leitura, para a própria comunidade escolar. Assim como enfatiza Moura (2006), ao dizer que a leitura deve ser o centro da atividade bibliotecária.

O Ministério da Educação, através dos Parâmetros Curriculares Nacionais de Língua Portuguesa, menciona a biblioteca escolar como importante processo para a formação do aluno:

O papel da escola (e principalmente do professor) é fundamental, tanto no que se refere à biblioteca escolar quanto à de classe, para organização de critérios de seleção de material impresso de qualidade e para orientação de alunos, de forma a promover a biblioteca [...], e a constituição de atitudes de cuidado e conservação do material disponível para consulta. Além disso, a organização do espaço físico, [...] deve garantir que todos os alunos tenham acesso ao material disponível. Mais do que isso, deve possibilitar ao aluno o gosto por frequentar aquele espaço, e dessa forma, o gosto pela leitura. (BRASIL, 1997, p. 61).

Apesar de todas as leis estabelecidas no sistema educacional do país que atestam a relevância da biblioteca nas escolas e sua grande importância como instrumento pedagógico na ação de ensino e aprendizagem, Andrade (2013) apresenta, a partir de um estudo de caso envolvendo bibliotecas escolares em uma cidade do interior do estado de São Paulo, que o profissional bibliotecário, em muitas bibliotecas, não está envolvido nos projetos pedagógicos do ambiente escolar, e sua práxis pouco agrega no processo de aprendizado dos alunos, pois não há uma parceria junto aos professores.

Como forma de otimizar a utilização da biblioteca na escola, tornando-a efetiva no processo de ensino e aprendizagem, é necessário que a mesma tenha profissionais qualificados, que haja integração desses profissionais com toda a equipe docente e que o projeto pedagógico da escola inclua a participação da biblioteca em sua ação pedagógica, não como um depósito de livros ou outros materiais, mas desenvolvendo um estreitamento na relação entre o bibliotecário, o professor e o aluno, produzindo e estimulando o processo de pesquisa e do letramento (ANDRADE, 2013; FRAGOSO, 2005; NEVES; RAMOS, 2010; PERROTTI, 1990). 
Estes são alguns conceitos que evidenciam a biblioteca escolar como um ambiente privilegiado para a aprendizagem, como um campo fértil para a relação do aluno com a leitura e, ainda, considerando a literatura como instrumento constitutivo e fundamental para a formação da criança como um leitor assíduo, culto, inteligente, criativo e crítico.

\section{Considerações finais}

No Brasil existem diversas políticas públicas que estimulam a criação de bibliotecas nas escolas, políticas que subsidiam estes espaços com livros e outros materiais bibliográficos. Contudo, falta organização, ordenação de recursos públicos para maior efetividade da legislação vigente. Falta comprometimento político para aplicação da legislação, sobretudo quanto à presença de um profissional bibliotecário para gerir as bibliotecas nas escolas.

A legislação federal reforça o papel da biblioteca nas escolas, que se constitui como um importante recurso para mediação no processo de ensino e aprendizagem, subsidiando o processo educacional. A biblioteca escolar tem o potencial de integrar todo o processo educativo das escolas, porém, não deve se organizar como uma estrutura independente e isolada. Pelo contrário, deve envolver toda comunidade escolar, como a direção, os professores e os bibliotecários, para que os projetos pedagógicos incluam a participação da biblioteca em suas ações pedagógicas, a fim de otimizar o desenvolvimento intelectual dos alunos.

É essencial que sejam promovidas formações continuadas com os professores, bibliotecários e demais técnicos que atuam nas bibliotecas escolares, tanto com o propósito de organização do acervo e do ambiente, a fim de produzir um espaço agradável e estimulador da leitura, quanto para uma imersão dos professores e alunos no letramento, de forma que os bibliotecários e docentes tenham adequadas condições para um efetivo trabalho na formação de leitores.

Ressaltamos, em consonância aos dizeres de Cosson (2018), que a escola, por meio dos professores, tem a missão de ensinar a ler, formar leitores, 
produzir o letramento, pois esta é uma considerável prática social. Para que essa função seja alcançada, é fundamental que as escolas tenham professores conscientes da importância da leitura, que sejam preparados, e que reconheçam a biblioteca como espaço apropriado a essa atividade, promovendo-a de forma agradável e prazerosa. Que as escolas tenham profissionais adequados e integrados em seus projetos, com ambiente adequado e bem estruturado para acolher os alunos e mantê-los, produzindo o interesse e o gosto pela prática da leitura.

\section{Referências}

ALCÂNTARA, A. A. R. Biblioteca escolar: um espaço de aprendizagem. 2013. 177 p. Dissertação (Mestrado Profissional em Gestão e Avaliação da Educação Pública) - Universidade Federal de Juiz de Fora, Juiz de Fora, 2013.

ANDRADE, T. F. Formação do bibliotecário escolar: estudo de caso sobre o curso de Biblioteconomia e Ciência da Informação da UFSCar. Biblioteca Escolar em Revista, Ribeirão Preto, v. 2, n. 1, p. 1-19, 2013.

BEZERRA, M. A. da C. O papel da biblioteca escolar: importância do setor no contexto educacional. CRB-8 Digital, São Paulo, v. 1, n. 2, p. 4-10, out. 2008.

BICHERI, A. L. A. de O.; ALMEIDA JÚNIOR, O. F. Bibliotecário escolar: um mediador de leitura. Biblioteca Escolar em Revista, Ribeirão Preto, v. 2, n. 1, p. 41-54, 2013.

BRASIL. Decreto $\mathbf{n}^{\mathbf{0}}$ 7.559, de 1 de setembro de 2011. Dispõe sobre o Plano Nacional do Livro e Leitura - PNLL e dá outras providências. Brasília, DF, 2011. Disponível em: http://www.planalto.gov.br/ccivil_03/_ato20112014/2011/decreto/D7559.htm. Acesso em: 22 jun. 2019.

BRASIL. Decreto no 9.099, de 18 de julho de 2017. Dispõe sobre o Programa Nacional do Livro e do Material Didático. Brasília, DF, 2017. Disponível em: http://www.planalto.gov.br/ccivil_03/_ato2015-2018/2017/decreto/D9099.htm. Acesso em: 19 jun. 2019.

BRASIL. Lei $\mathbf{n}^{\mathbf{0}} \mathbf{4 . 0 8 4}$, de 30 de junho de 1962. Dispõe sobre a profissão de bibliotecário e regula seu exercício. Brasília, DF, 1962. Disponível em: http://www.planalto.gov.br/ccivil_03/LEIS/1950-1969/L4084.htm. Acesso em: 1 mar. 2019.

BRASIL. Lei no 9.674, de 25 de junho de 1998. Dispõe sobre o exercício da profissão de Bibliotecário e determina outras providências. Brasília, DF, 1998a. 
Disponível em: http://www.planalto.gov.br/ccivil_03/LEIS/L9674.htm. Acesso em: 1 mar. 2019.

BRASIL. Lei $\mathbf{n}^{\mathbf{0}} \mathbf{1 0 . 7 5 3}$, de 30 de outubro de 2003. Institui a Política Nacional do Livro. Brasília, DF, 2003. Disponível em: https://www2.camara.leg.br/legin/fed/lei/2003/lei-10753-30-outubro-2003497306-publicacaooriginal-1-pl.html. Acesso em: 22 jun. 2019.

BRASIL. Lei $\mathbf{n}^{\mathbf{0}} \mathbf{1 2 . 2 4 4}$, de 24 de maio de 2010. Dispõe sobre a universalização das bibliotecas nas instituições de ensino do país. Brasília, DF, 2010. Disponível em: http://www.planalto.gov.br/ccivil_03/_Ato20072010/2010/Lei/L12244.htm. Acesso em: 6 dez. 2018.

BRASIL. Lei $\mathbf{n}^{\mathbf{0}}$ 13.005, de 25 de junho de 2014. Aprova o Plano Nacional de Educação - PNE e dá outras providências. Brasília, DF, 2014. Disponível em: http://www.planalto.gov.br/ccivil_03/_ato2011-2014/2014/lei/113005.htm. Acesso em: 22 jun. 2019.

BRASIL. Lei $\mathbf{n}^{\circ}$ 13.696, de 12 de julho de 2018. Institui a Política Nacional de Leitura e Escrita. Brasília, DF, 2018. Disponível em: http://www.planalto.gov.br/ccivil_03/_ato2015-2018/2018/Lei/L13696.htm. Acesso em: 22 jun. 2019.

BRASIL. Ministério da Educação. Programa Nacional Biblioteca da Escola (PNBE). Brasília, DF, 2020a. Disponível em:

http://portal.mec.gov.br/programa-nacional-biblioteca-da-escola. Acesso em: 10 dez. 2020.

BRASIL. Ministério da Educação. Programa Nacional do Livro e do Material Didático (PNLD). Brasília, DF, 2020b. Disponível em:

http://portal.mec.gov.br/component/content/article?id=12391:pnld. Acesso em: 10 dez. 2020.

BRASIL. Ministério da Educação. Secretaria de Educação Fundamental. Parâmetros Curriculares Nacionais: língua portuguesa. Brasília, DF, 1997. 144 p. Disponível em: http://portal.mec.gov.br/seb/arquivos/pdf/livro02.pdf. Acesso em: 14 fev. 2019.

BRASIL. Ministério da Educação. Secretaria de Educação Fundamental. Parâmetros Curriculares Nacionais: terceiro e quarto ciclos do ensino fundamental: língua portuguesa. Brasília, DF, 1998b. 106 p. Disponível em: http://portal.mec.gov.br/seb/arquivos/pdf/portugues.pdf. Acesso em: 14 fev. 2019.

BRITTO, L. P. L. No lugar da leitura: biblioteca e formação. Rio de Janeiro: Edições Brasil Literário, 2016. 93 p. 
CALDIN, C. F.; FLECK, F. de O. Organização de biblioteca em escola pública: o caso da escola de educação básica Dom Jaime de Barros Câmara. Revista ACB: biblioteconomia em Santa Catarina, Florianópolis, v. 9, n. 1, p. 155-165, 2003/2004.

CAMPELlO, B. S. Apresentação. In: CAMPELLO, B. S. et al. A biblioteca escolar: temas para uma prática pedagógica. 2. ed. Belo Horizonte: Autêntica, 2012. p. 7-8.

CAMPELLO, B. S. (coord.). Biblioteca escolar como espaço de produção do conhecimento: parâmetros para bibliotecas escolares. Belo Horizonte: Autêntica, 2010. 33 p.

COSSON, R. Letramento literário: teoria e prática. 2. ed. São Paulo: Contexto, 2018. 139 p.

DURBAN ROCA, G. Biblioteca escolar hoje: recurso estratégico para a escola. Porto Alegre: Penso, 2012. 110 p.

FRAGOSO, G. M. Biblioteca na escola. Revista ACB: biblioteconomia em Santa Catarina, São José, v. 7, n. 1, p. 124-131, 2002.

FRAGOSO, G. M. Biblioteca na escola: uma relação a ser construída. Revista ACB: biblioteconomia em Santa Catarina, Florianópolis, v. 10, n. 2, p. 169-173, jan./dez. 2005.

GASQUE, K. C. G. D. Letramento informacional: pesquisa, reflexão e aprendizagem. Brasília, DF: Ed. FCI/UnB, 2012. 181 p.

HILLESHEIM, A. I. de A.; FACHIN, G. R. B. Biblioteca escolar e a leitura. Revista ACB: biblioteconomia em Santa Catarina, São José, v. 8/9, n. 1, p. 3545, 2003/2004.

INSTITUTO NACIONAL DE ESTUDOS E PESQUISAS EDUCACIONAIS ANÍSIO TEIXEIRA. Censo escolar da educação básica 2013: resumo técnico. Brasília, DF: INEP, 2014. 38 p.

INTERNATIONAL FEDERATION OF LIBRARY ASSOCIATIONS AND IN STITUTIONS. Manifesto IFLA/UNESCO para biblioteca escolar. São Paulo: IFLA, 2000. Disponível em: https://www.ifla.org/files/assets/schoollibraries-resource-centers/publications/school-library-manifesto-pt-brazil.pdf. Acesso em: 22 fev. 2019.

INTERNATIONAL FEDERATION OF LIBRARY ASSOCIATIONS AND IN STITUTIONS. Manifesto da IFLA/UNESCO sobre bibliotecas. São Paulo: IFLA, 1994. Disponível em: https://www.ifla.org/files/assets/publiclibraries/publications/PL-manifesto/pl-manifesto-ptbrasil.pdf. Acesso em: 12 mar. 2019. 
MENDES, I. A origem da "biblioteca". 2012. Disponível em: http://www.etimologista.com/2012/11/a-origem-da-biblioteca.html. Acesso em: 18 fev. 2019.

MILANESI, L. O que é biblioteca. 3. ed. São Paulo: Brasiliense, 2002. 116 p. (Coleção Primeiros Passos).

MOURA, M. A. Leitor-bibliotecário: interpretação, memória e as contradições da subjetividade em processos de representação informacional. In: NAVES, M. M. L.; KURAMOTO, H. (org.). Organização da informação: princípios e tendências. Brasília, DF: Briquet de Lemos, 2006. p. 22-35.

NEVES, N. V.; RAMOS, F. B. O espaço da biblioteca escolar: análise das condições de mediação de leitura. In: CONGRESSO INTERNACIONAL DE FILOSOFIA E EDUCAÇÃO, 5., 2010, Caxias do Sul. Anais [...]. Caxias do Sul: Ed. UCS, 2010.

ORIÁ, R. Bibliotecas escolares no Brasil: uma análise da aplicação da Lei ${ }^{\circ}$ 12.244/2010. Brasília, DF: Câmara dos Deputados, 2017. 32 p.

PERROTTI, E. Confinamento cultural, infância e leitura. São Paulo: Summus, 1990. 108 p. (Novas buscas em educação, 38).

PIMENTEL, G.; BERNARDES, L.; SANTANA, M. Biblioteca escolar. Brasília: Ed. UnB, 2007. 117 p.

VIEIRA, E. dos P. Biblioteca escolar: visão dos usuários da biblioteca da escola de Educação Básica Altamiro Guimarães, em Antônio Carlos, SC. 2013. 53 p. Trabalho de Conclusão do Curso (Graduação em Biblioteconomia) Universidade Federal de Santa Catarina, Florianópolis, 2013.

\title{
Public policy: legal framework for school libraries
}

\begin{abstract}
Considering the school library as a space for the training of readers and pedagogical resource, we present a literature review on legislation in favor of the school library, its structure, equipment, collections, its use, the importance of having a qualified professional and the interrelation the librarian with the teachers, so that the teaching and learning process of students is facilitated and enhanced. In order to contribute and promote access to and use of the book, the federal government has regulatory frameworks for library, book and reading policy. We also discussed the need for effective and continuous training for librarians, teachers and reading agents, in order to strengthen the library as a democratic environment for access to knowledge, for reading actions, based on
\end{abstract}


the objectives, functions and mission of the school library. The library is an instrument for the development of culture and also of the school curriculum, as it nourished reading and, consequently, generates learning, but for this process to be effective, an intimate partnership with teachers is necessary, and government policies must be made, foreseeing and consolidating the necessary investments to the school library.

Keywords: Educational library; Library - Legislation; School library; Literacy

Recebido: 09/03/2021

Aceito: 02/06/2021

\section{Declaração de autoria}

Concepção e elaboração do estudo: Márcio Barbosa de Assis, Ilsa do Carmo Vieira Goulart.

Coleta de dados: Márcio Barbosa de Assis, Ilsa do Carmo Vieira Goulart Análise e interpretação de dados: Márcio Barbosa de Assis, Ilsa do Carmo Vieira Goulart.

Redação: Márcio Barbosa de Assis, Ilsa do Carmo Vieira Goulart.

Revisão crítica do manuscrito: Márcio Barbosa de Assis, Ilsa do Carmo Vieira Goulart.

\section{Como citar}

ASSIS, Márcio Barbosa de; GOULART, Ilsa do Carmo Vieira. Políticas públicas: marco legal para as bibliotecas escolares. Em Questão: Porto Alegre, v. 28, n. 1, p. 327-352, 2022. DOI: http://dx.doi.org/10.19132/18085245281.327-352 